\title{
The Synthesis of Peculiar Structure of Springlike Multiwall Carbon Nanofibers/Nanotubes via Mechanothermal Method
}

\author{
Sahebali Manafi, ${ }^{1}$ Mohammad Reza Rahimipour, ${ }^{2}$ Iman Mobasherpour, ${ }^{2}$ \\ and Atefeh Soltanmoradi ${ }^{1}$
}

${ }^{1}$ Department of Ceramics, Islamic Azad University, Shahrood Branch, Shahrood, Iran

${ }^{2}$ Materials and Energy Research Center, P.O. Box 14155-4777, Tehran, Iran

Correspondence should be addressed to Sahebali Manafi, ali_manafi2005@yahoo.com

Received 26 September 2011; Accepted 14 April 2012

Academic Editor: Jianyu Huang

Copyright (C) 2012 Sahebali Manafi et al. This is an open access article distributed under the Creative Commons Attribution License, which permits unrestricted use, distribution, and reproduction in any medium, provided the original work is properly cited.

\begin{abstract}
Mechanothermal (MT) method is one of the methods used for large-scale production of carbon nanotubes/nanofibers. The different peculiar morphologies of carbon allotropes are introduced with an extraordinary structure for the first time by MT method. In this paper, the influence of milling time and annealing temperature on the crystallinity and morphology of the synthesized nanopowders was investigated. Surprisingly, in this investigation, we report the synthesis of springlike multiwalled carbon nanofibers (S-MWCNFs) by a two-step annealing of milled graphite in an Ar atmosphere. On the other hand, the MT method could be used for the preparation of suitable structures with applications in nanocomposite materials, which is an important task in the era of nanotechnology.
\end{abstract}

\section{Introduction}

Carbon nanotubes have attracted considerable interest since their discovery by Iijima in 1991 [1]. Carbon nanotubes have aroused great interest recently because of their unique physical properties, which span a wide range from structural to electronic. For example, nanotubes have a low weight and high elastic modulus, and thus they are predicted to be the strongest fibers and widely touted as attractive candidates for use as fillers in composite materials due to their extremely high Young's modulus, stiffness, and flexibility [2-6]. These latter applications will require vast quantities of nanotubes at competitive prices to be economically feasible. Moreover, reinforcing applications may not require ultrahigh purity nanotubes. On the other hand, functionalization of nanotubes to facilitate interfacial bonding within composites will naturally introduce defects into the tube walls; lessening morphologies are needed for specified applications of CNTs. For instance, usually it is needed to prepare knotted CNTs to improve in rich interfacial adhesion, which can lead to nanotube aggregation within the matrix composites. So, there are many methods of producing these nanomaterials, including electric arc discharge [1,7], laser evaporation [8], chemical vapor deposition (CVD), catalytic CVD [9-19], hydrothermal treatment [20], and mechanothermal process in which graphite powders were first mechanically ground at room temperature and then annealed at $1400^{\circ} \mathrm{C}$ [21], but little is known about the possibilities of mechanothermal processing aimed to the synthesis of carbon nanostructures in different conditions. Although significant research progress has been made to synthesize carbon nanomaterials, but developing an easy approach to large-scale production of carbon nanotubes has still been limited to date. On the other hand, most of the synthesizing methods are complicated and uncontrollable. More recently, we have suggested that using washable supported catalysts is accompanied by valuable advantages and with an extraordinary structure [22-28]. Herein, we use an efficient method for the controlled synthesis of multiwall carbon nanotubes/nanofibers by mechanical activation-assisted annealed process. springlike MWCNFs and MWCNTs were fabricated with advantages of mass production, low cost, and high yield without adding any presynthesized $\mathrm{Fe} / \mathrm{Co} / \mathrm{Ni}$ nanocatalysts. Finally, we report a simple and convenient synthesis method of CNFs/CNTs with 


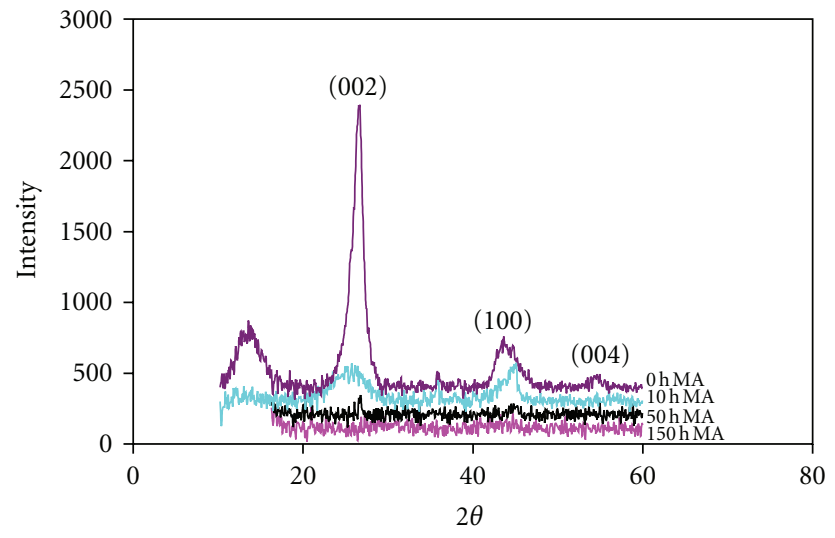

Figure 1: The X-ray diffraction spectra of mechanically alloyed graphite powders at different milling times: $0 \mathrm{~h}, 10 \mathrm{~h}, 60 \mathrm{~h}$ and $160 \mathrm{~h}$.

outstanding morphology structure. This method needs no complicated process, relatively low cost and economically.

\section{Experimental Procedures}

Elemental graphite flakes $(99.9 \%<100 \mu \mathrm{m})$ with a purity of $99.8 \%$ were mechanically ground in a purified argon atmosphere. Four grams with ten steel balls of diameter $15 \mathrm{~mm}$ were used in the mechanical activation (MA) process. The ball-to-powder weight ratio was kept at 20:1. Mechanical activation was carried out at ambient temperature and at a rotational speed (cup speed) of $700 \mathrm{rpm}$ in a planetary ball mill. The mechanical activation (MA) process was interrupted at regular intervals with a small amount of the MAed powder taken out from the vial to study changes in the microstructures at selected milling duration. On the other hand, mechanical activation was carried out in a planetary ball mill that was directly connected to a closed glove box. In order to avoid oxidization, loading and unloading of powders were operated in a glove box under high pure argon atmosphere.The final gas pressure in the vial was kept to be $0.1 \mathrm{MPa}$. The Fe/Cr contents of the final sample introduced from the milling media and the starting materials were measured by the inductively coupled plasma (ICP) method. Meanwhile, we removed Fe/Cr contamination by treatment with a $30 \mathrm{~mL}$ aqueous solution containing $2 \mathrm{~mL}$ of hydrochloric acid (36.5 wt.\%), $5 \mathrm{~mL}$ of $\mathrm{H}_{2} \mathrm{O}_{2}$ (30 wt.\%), and $20 \mathrm{~mL}$ of distilled water $\left(\mathrm{HCl}: \mathrm{H}_{2} \mathrm{O}_{2}: \mathrm{H}_{2} \mathrm{O}=2: 5: 20 \mathrm{~V} / \mathrm{V}\right)$ at room temperature for $12 \mathrm{~h}$. After full amorphization, onestep and two-step annealing were applied on MAed graphite to investigate the grain growth during the heat treatment. The crystal phase was determined with powder X-ray diffraction. For these experiments, a Siemens diffractometer $(30 \mathrm{kV}$ and $25 \mathrm{~mA}$ ) with the $\mathrm{K}_{\alpha 1}$, radiation of copper $(\lambda=1.5406 \hat{\AA})$, was used. The structural and compositional information of the product materials was obtained with scanning electron microscopy (SEM, Philips XL30), energy dispersive X-ray spectroscopy (SEM/EDX, XL30), field emission transmission electron microscopy, and selected area electron diffraction (FETEM/SAED, Philips CM200 transmission electron

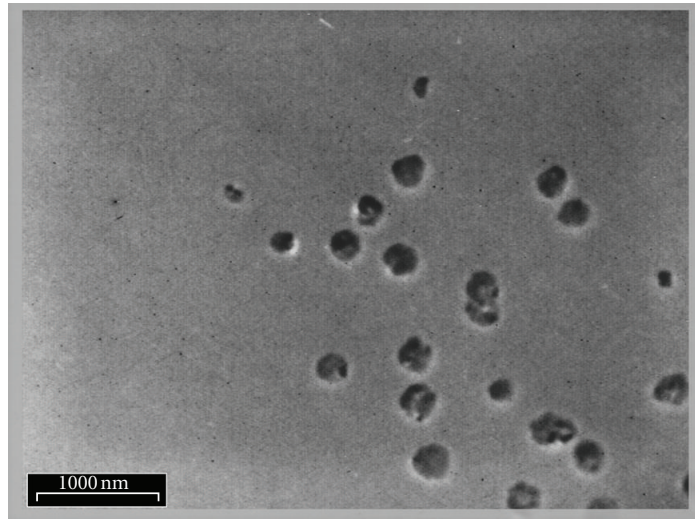

(a)

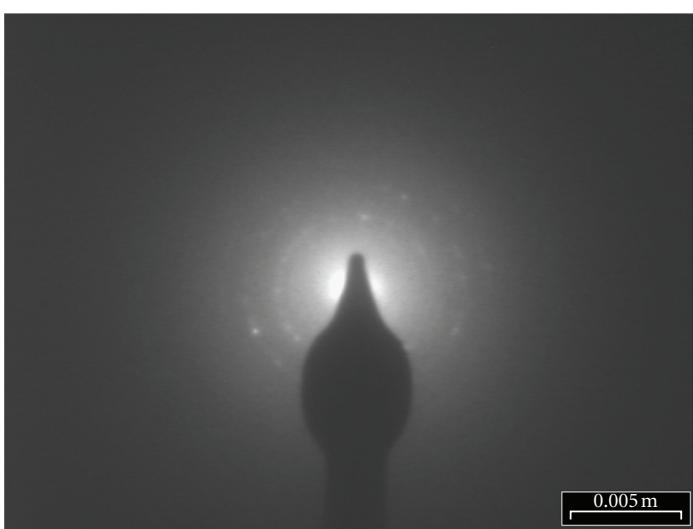

(b)

FIGURE 2: Mechanically milled powder by a mechanical activation via planetary mill: (a) transmission electron microscope (TEM) and (b) selected area electron diffraction pattern (SAED).

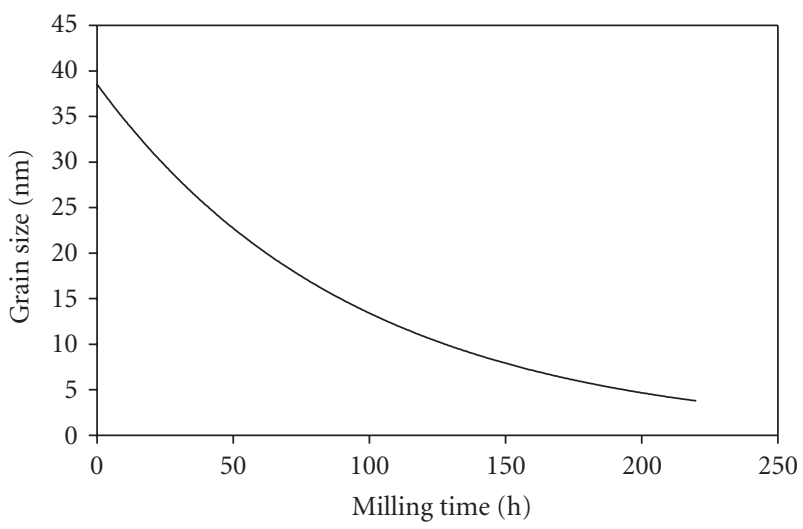

FIGURE 3: The grain size of graphite as function of mechanical activation times.

microscope operated at $200 \mathrm{kV}$ ). Specific surface areas (SSAs) of carbon/carbon nanotubes were also measured by the Brunauer-Emmett-Teller (BET) method. The BET surface areas, $S_{\mathrm{BET}}$, of the samples were determined from $\mathrm{N}_{2}$ adsorption-desorption isotherms obtained at $77 \mathrm{~K}$ using an 


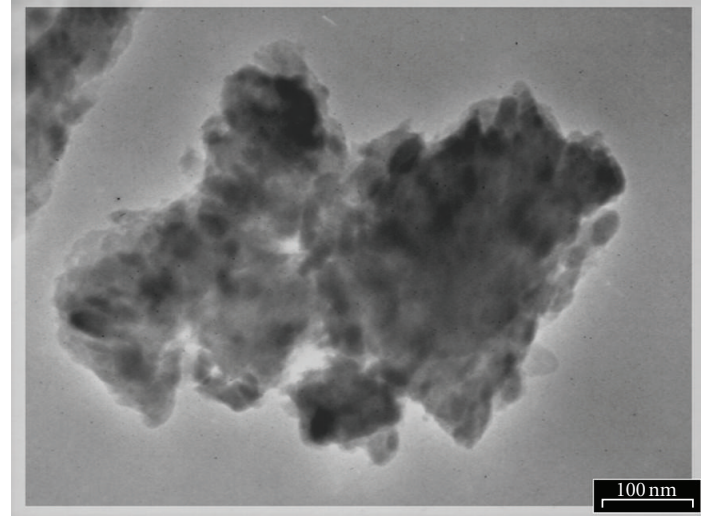

Figure 4: MAed graphite powders for $150 \mathrm{~h}$ in argon gas atmosphere.

ASAP 2010 surface area analyzer. The Brunauer-EmmettTeller (BET) method is the most widely used procedure for the determination of the surface areas of solid materials and involves the use of the BET equation:

$$
\frac{1}{W\left[\left(P_{0} / P\right)-1\right]}=\frac{1}{W_{m} C}+\frac{C-1}{W_{m} C}\left(\frac{P}{P_{0}}\right),
$$

in which $W$ is the weight of gas adsorbed at a relative pressure of $P / P_{0}$, and $W_{m}$ is the weight of adsorbate constituting one monolayer of surface coverage. The term $C$, the BET $C$ constant, is related to the energy of adsorption in the first adsorbed layer, and consequently, its value is an indication of the magnitude of the adsorbent-adsorbate interactions. When the range of $P / P_{0}$ is $0.05-0.35$, a line will be obtained. Through the slope and intercept, the adsorbate monolayer saturation amount $\left(V_{m}\right)$ can be obtained. The BET surface area equation is

$$
S_{\mathrm{BET}}=V_{m} N_{0} \frac{\sigma}{22400 \mathrm{~W}},
$$

where $N_{0}$ is Avogadro's number and $\sigma$ is the cross-sectional area of a single molecule. Raman spectra were taken at room temperature under ambient condition using an Almega Raman spectrometer with an $\mathrm{Ar}^{+}$at an excitation wavelength of $514.5 \mathrm{~nm}$. The crystalline size, $D$, was estimated by Williamson-Hall [29]:

$$
\beta \cos \theta=2 \varepsilon \sin \theta+0.9 \frac{\lambda}{D},
$$

where $\lambda$ is the wavelength of the $\mathrm{X}$-ray, $\beta$ the full width at half maximum (FWHM), $\theta$ the Bragg angle, and $\varepsilon$ the microstrain.

\section{Results and Discussion}

XRD patterns of graphite powder mechanically mixed in argon atmosphere for several activation times are shown in Figure 1. Further milling (after $150 \mathrm{~h} \mathrm{MA}$ ) caused no change in XRD patterns except the broadening of the peaks. So, this broadening can be attributed to the decrease of grain size and increasing of strain in the lattice. In general, we can conclude that this method is a very successful method for amorphous of graphite powders by mechanical activation (MA).

The constitution of this starting powder corresponds to the elemental graphite powder and so, the diffraction intensities drastically decreased after mechanical activation (MA). The diffraction peaks corresponding to the graphite (particularly the peak at about $2 \theta=26.6^{\circ}$ ) almost disappeared at an activating time of $10 \mathrm{~h}$. The crystallite size of the graphite after mechanical activation for $5 \mathrm{~h}$ is approximately $D=30.1 \mathrm{~nm}$, where that before MA is approximately $D=31.1$ (Table 1). An additional MA process in the argon atmosphere (Figure 1) in which, diffraction intensities corresponding to the graphite decrease gradually with increasing activating time at the diffraction peaks at around $2 \theta=$ $26.6^{\circ}$ cannot be eliminated after an activating time of $100 \mathrm{~h}$, suggesting that the formation of an amorphous-like phase or very fine particles has been strongly enhanced in the argon atmosphere after an activating time of $150 \mathrm{~h}$. Figure 2 shows the transmission electron micrograph (Figure 2(a)) and selected area electron diffraction pattern (Figure 2(b)) of graphite nanostructures synthesizing according to the method described previously. It is readily observed that the nanostructures are in a high ultrafine dispersion and the average crystalline size is $10 \mathrm{~nm}$. The electron diffraction (ED) pattern of the MAed graphite (Figure 2(b)) exhibits two very weak diffuse rings, indicating highly disordered wall in milled graphite. On the other hand, the electron diffraction pattern reveals that the carbon nanostructures have an amorphous structure. At the same time, this result is consistent with the X-ray diffraction (XRD) pattern. We believe that the very small size and the amorphous structure are due to the high-energy ball milling of the graphite powders activated by planetary mill. Also, Jiang and Chen [30] recently developed a thermodynamic quantitative model to describe the phase transitions of nanocarbon as functions of its size and temperature through systematically considering the effects of surface stresses and surface energies. The fine nanosize amorphous structure of pure carbon nanostructures is thermodynamically unstable, owing to the high amount of free energy. Therefore, crystallization at a temperature regime might be expected.

The milled powders had an average crystallite size of about $5-10 \mathrm{~nm}$ as determined by the Williamson-Hall method as shown in Table 1 and Figure 3. Crystallite size values determined in this way may be low when the concentration of defects in the sample is higher compared to that in the reference large-particulate powder. The BET areas are strongly different for all samples and between 5.5 and $211.2 \mathrm{~m}^{2} / \mathrm{g}$ as presented in Table 1 . In the steady state, the BET surface area of the MAed powders was determined at about $211.2 \mathrm{~m}^{2} / \mathrm{g}$ for several samples $\left(\mathrm{C}_{200}, \mathrm{C}_{210}, \mathrm{C}_{220}\right.$, etc. $)$.

$D$ is the average crystallite size, determined by the Williamson-Hall; SA is the specific surface area, determined by the BET-method.

Measuring the surface area of carbon nanostructures via nitrogen adsorption by Brunauer-Emmet-Teller (BET) method revealed a specific surface area of $211.2 \mathrm{~m}^{2} / \mathrm{g}$ which seems relevant for surface area dependent applications such 


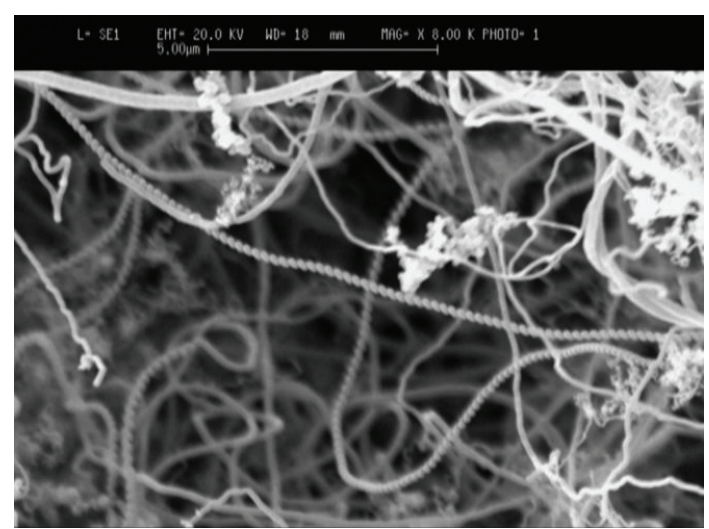

(a)

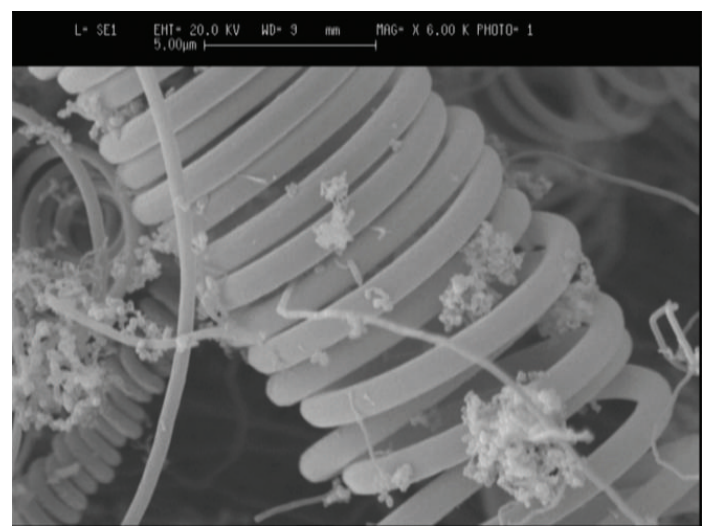

(c)

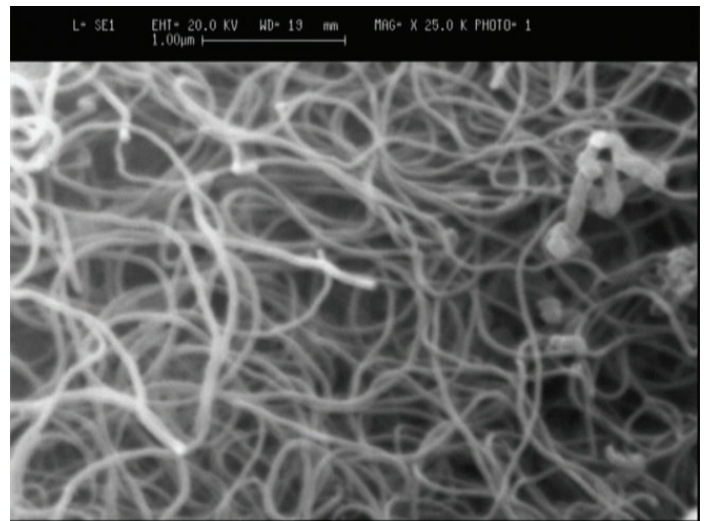

(e)

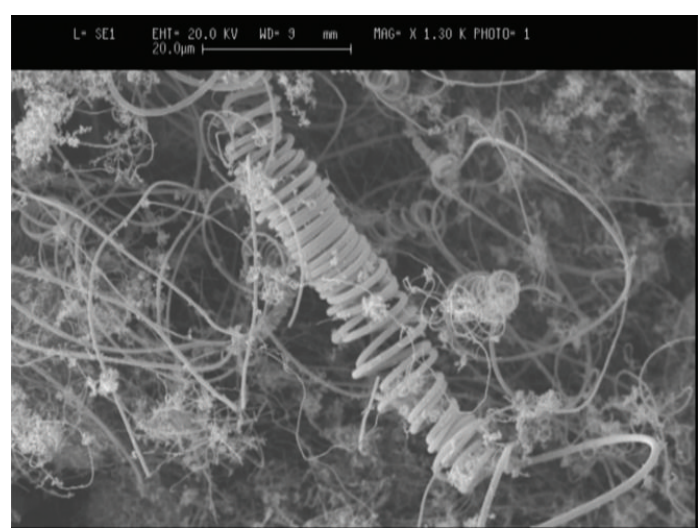

(b)

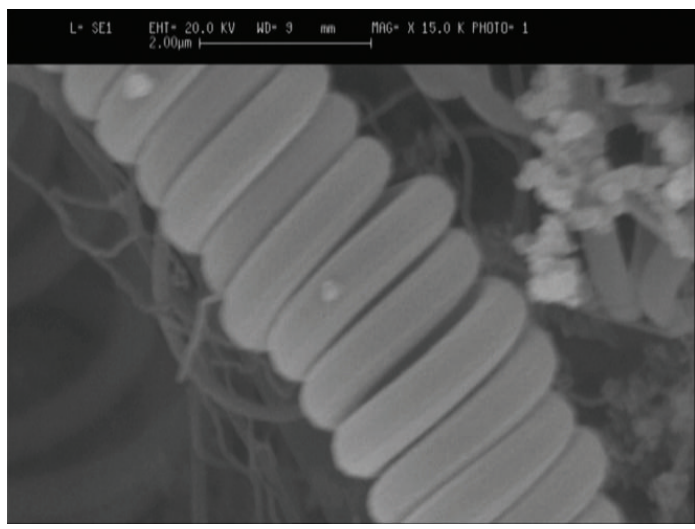

(d)

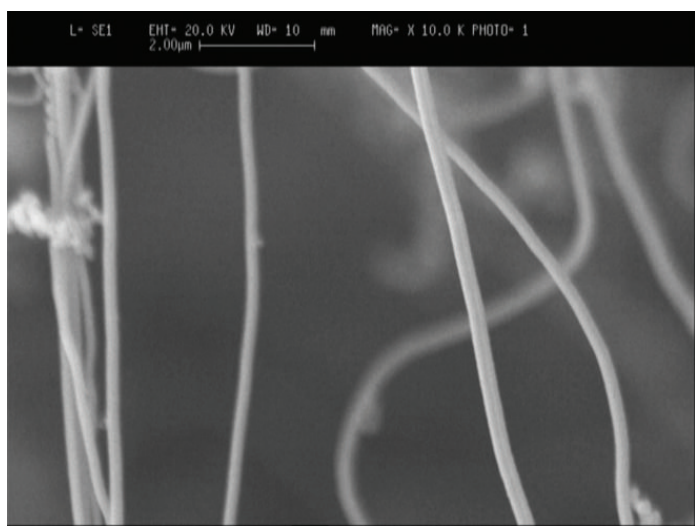

(f)

FIGURE 5: SEM images of MAed graphite powders for $150 \mathrm{~h}$ after one-step and two-step annealing with different morphologies: (a) high yield springlike MWCNFs (two-step), (b) individual MWCNFs with ultrahigh aspect ratio (two-step), (c) springlike MWCNFs encapsulated with carbon nanotubes (two-step), (d) S-MWCNF with an ultrahigh crystallinity structure (two-step), (e) high yield springlike MWCNTs (one-step), and (f) aligned arrays of MWCNTs (one-step).

as diffusion process. Assuming that all particles have spherical and theoretical density and form $d_{\mathrm{BET}}=6 / S \cdot \rho$, where $S$ is the surface area and $\rho$ is the particle density $\left(2.1 \mathrm{~g} / \mathrm{cm}^{3}\right.$ for graphite), a BET particle diameter, $d_{\mathrm{BET}}$, of about $20 \mathrm{~nm}$ is found for these nanoparticles. At the same time, these results are consistent with the HRTEM image observations. Therefore, the obtained results of specific area $(\mathrm{SA})$, crystallite size $(D)$ for milled graphite indicate that graphite particles are highly chemically active.

According to TEM micrographs of the powders mechanically milled for $150 \mathrm{~h}$ in argon gas atmosphere shown in Figure 4, MAed powders are an ultrafine spherical particle 


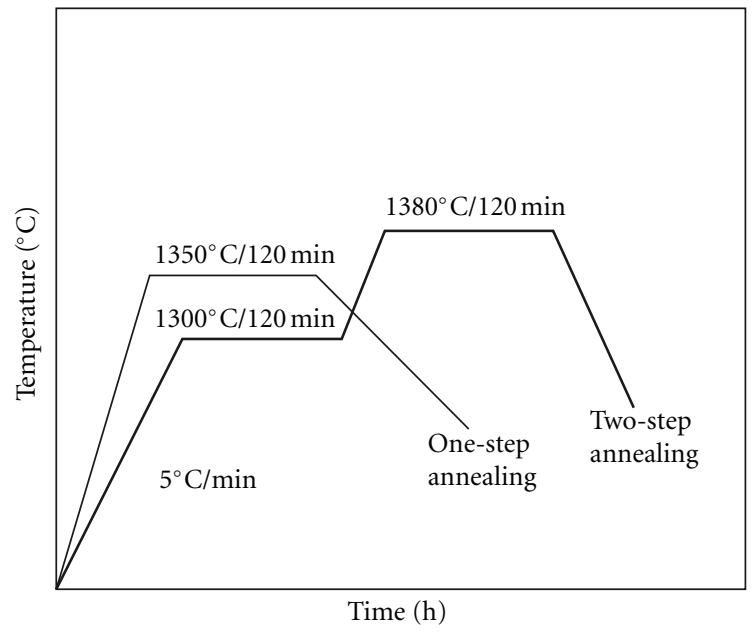

(a)

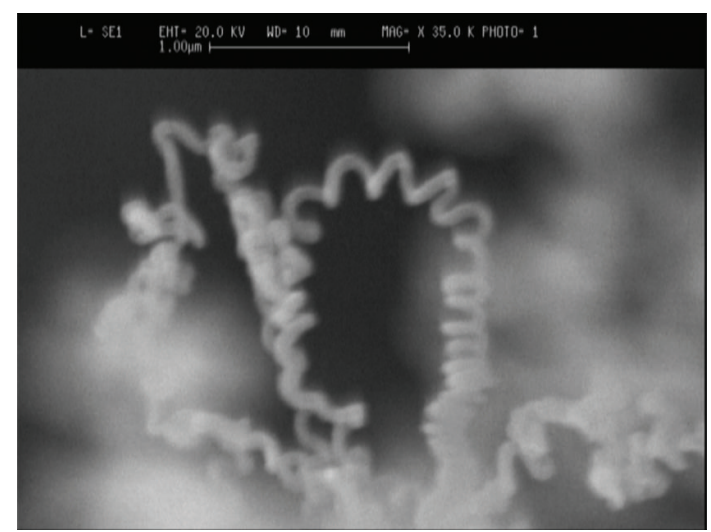

(b)

FIGURE 6: (a) Schematic diagram of annealing patterns to synthesize MWCNTs/S-MWCNFs by mechanothermal method and (b) SMWCNTs with ultrahigh flexible and toughness.

powder with approximately $100 \pm 20$ nanometers in size. Because of highly chemically active carbon atoms, these are strongly agglomerated.

Interestingly, Figures 5(a)-5(f) show the SEM different images of MAed graphite powders (the sample of $\mathrm{C}_{150}$ ) after one-step and two-step annealing. On the other hand, the heating program is indicated in Figure 6(a). A two-step annealing procedure was applied; that is, the samples were first heated to $1300^{\circ} \mathrm{C}$ at rate of $5^{\circ} \mathrm{C} / \mathrm{min}$ and held there for $120 \mathrm{~min}$, and they were then further heated to $1380^{\circ} \mathrm{C}$ at a rate of $5^{\circ} \mathrm{C} / \mathrm{min}$ and held there for $120 \mathrm{~h}$ under $\mathrm{Ar}$ atmosphere. Furthermore, the usage of a two-step annealing condition and a suitable mechanical activation are the two crucial keys in ensuring the formation of S-MWCNFs under the mechanothermal method. However, until now the role of annealing for the formation of S-MWCNFs is not clear. SEM observations in a wide field show that the powders prepared with the heat-treated $\left(\mathrm{C}_{150}\right)$ contain much more nanotubes/nanofibers with peculiar structure namely. springlike multiwall carbon nanofibers (S-MWCNFs). The nanotubes
TABLE 1: Characteristic of different samples used to investigate during milling.

\begin{tabular}{lccc}
\hline $\begin{array}{l}\text { Milling } \\
\text { time }(h)\end{array}$ & $\begin{array}{c}\text { Sample } \\
(\mathrm{Id})\end{array}$ & $\begin{array}{c}\text { S. A. } \\
\left(\mathrm{m}^{2} / \mathrm{g}\right)\end{array}$ & $\begin{array}{c}\text { Crystallite size }=D \\
(\mathrm{~nm})\end{array}$ \\
\hline 0 & $\mathrm{C}_{0}$ & 5.5 & 31.1 \\
5 & $\mathrm{C}_{5}$ & 21.2 & 30.1 \\
10 & $\mathrm{C}_{10}$ & 25.8 & 29.8 \\
30 & $\mathrm{C}_{30}$ & 35.1 & 27.4 \\
50 & $\mathrm{C}_{50}$ & 45.6 & 25.4 \\
60 & $\mathrm{C}_{60}$ & 50.1 & 24.6 \\
80 & $\mathrm{C}_{80}$ & 62.5 & 22.1 \\
90 & $\mathrm{C}_{90}$ & 70.2 & 20.1 \\
100 & $\mathrm{C}_{100}$ & 78.9 & 18.5 \\
120 & $\mathrm{C}_{120}$ & 115.2 & 13.9 \\
130 & $\mathrm{C}_{130}$ & 145.2 & 11.2 \\
140 & $\mathrm{C}_{140}$ & 175.5 & 8.5 \\
150 & $\mathrm{C}_{150}$ & 200.5 & 5.2 \\
160 & $\mathrm{C}_{160}$ & 205.5 & 4.9 \\
170 & $\mathrm{C}_{170}$ & 207.4 & 4.8 \\
180 & $\mathrm{C}_{180}$ & 209.1 & 4.7 \\
190 & $\mathrm{C}_{190}$ & 209.5 & 4.8 \\
200 & $\mathrm{C}_{200}$ & 211.2 & 4.8 \\
210 & $\mathrm{C}_{210}$ & 211.2 & 4.8 \\
220 & $\mathrm{C}_{220}$ & 211.2 & 4.8 \\
\hline
\end{tabular}

are knotted and stretchy in appearance and are mainly SMWCNFs (for two-step annealing in Figure 5(a)) which will be demonstrated later. In the SEM observation of $\mathrm{C}_{150}$, a few multiwall carbon nanotubes (MWCNTs) were sporadically observed (for one-step annealing in Figure 5(e)). However, for the samples $\mathrm{C}_{70}, \mathrm{C}_{90}$, and $\mathrm{C}_{100}$, no CNTs or CNFs were found in all observations after suitable annealing. A detailed study of the growth mechanism of the S-MWCNFs is underway. The interesting structure and physical properties (high aspect ratio ca. 1000 and low density) of the SMWCNFs make it an obvious choice as obvious applications. In this way, Figure 6(b) shows that an individual MWCNF with a suitable aspect ratio was bent like a spring but still was not broken, indicating that the fiber is very flexible and tough for reinforcement in nanocomposite materials. Finally, in this investigation, an effective method was developed for the formation of ultracrystallinity S-MWCNTs and MWCNTs. As a matter of fact, the MT method guarantees production of CNT/CNF for different applications.

Meanwhile, TEM images of mechanically activated graphite powders after a one-step and two-step annealing are shown in Figures 7(a)-7(d). In Figures 5(a) and 5(b), many S-MWCNFs can be observed, which is consistent with the SEM observation. By TEM observation, we have found that most of nanofibers in the annealed powders are SMWCNTs (for two-step annealing). Also, we confirmed that synthesized MWCNTs have fibrous structures with ultrahigh uniform grade (Figures 7(c) and 7(d)). 


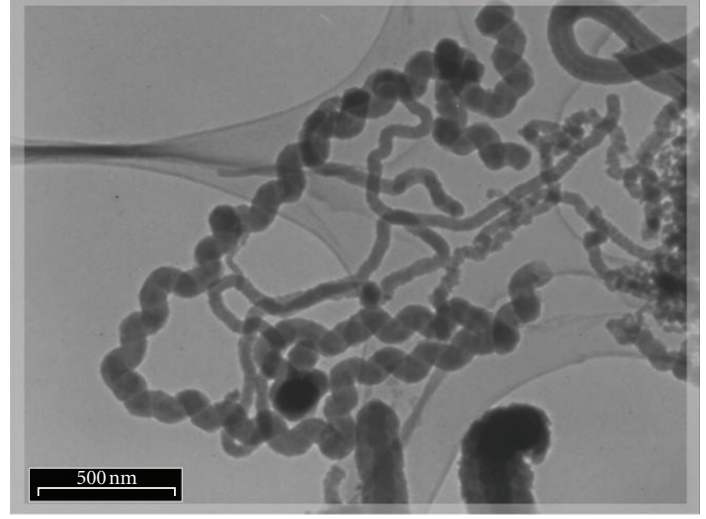

(a)

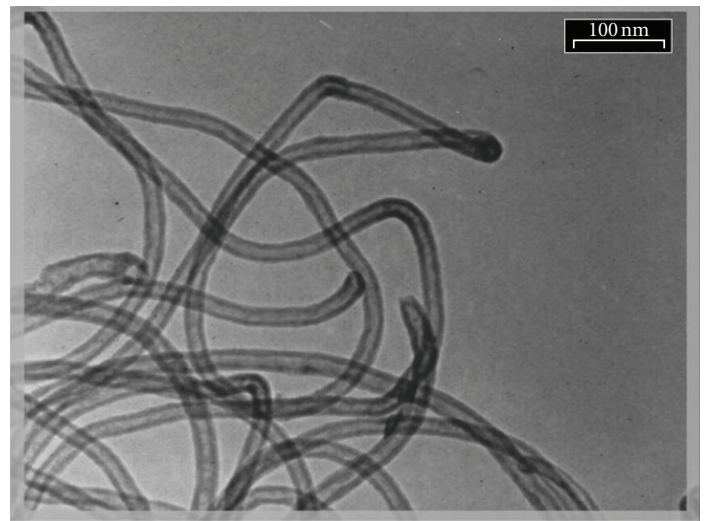

(c)

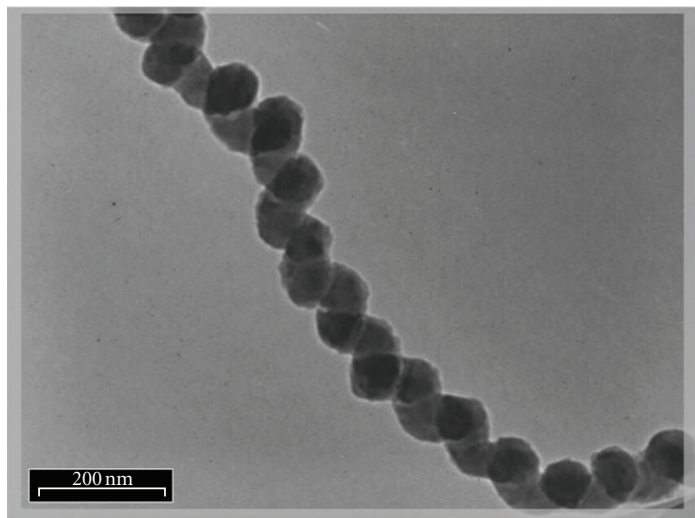

(b)

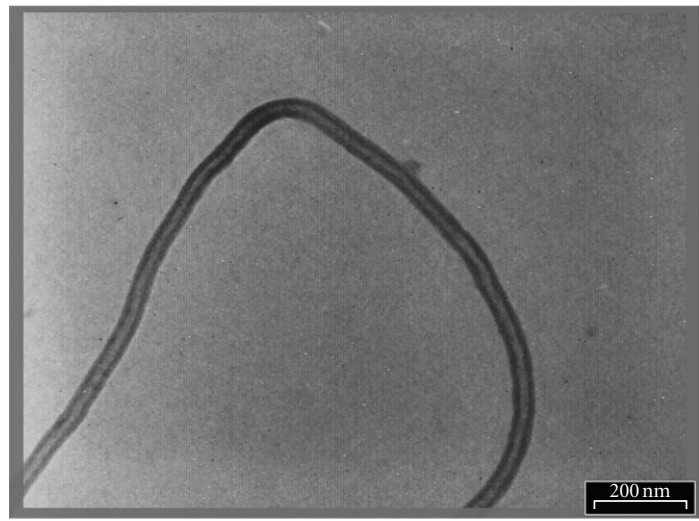

(d)

FIGURE 7: TEM images of MAed graphite powders for $150 \mathrm{~h}$ after one-step and two-step annealing with different morphologies: (a) springlike MWCNFs encapsulated with carbon nanotubes (two-step), (b) individual MWCNFs (two-step), (c) MWCNTs with an ultrahigh crystallinity structure (one-step), and (d) individual MWCNTs with narrow channels (one-step).

The selected area electron diffraction (SAED) pattern (Figure 8(a)) exhibits a pair of weak rings but strong spots for (002), together with a ring for (100) and a pair of weak arcs for (004) diffractions. The appearance of (002) diffractions as a pair of spots indicates some orientation of the (002) planes in the carbon tubes [31]. The yield of the prepared MWCNTs estimated by TEM observations is about $95 \%$ relative to the samples on copper grids, and the much less contents of the obtained product are nanoparticles. Thus, the high yield efficiency of this approach for the synthesis of MWCNT can be concluded, with an ultrahigh crystallinity and an excellent yield rather than previous works. In further investigation, the MWCNTs were analyzed by HRTEM in detail, and all nanostructures showed uniform lattice fringes, meaning that no amorphous product was formed. Figure $8(\mathrm{~b})$ is the HRTEM image of a single CNT, which clearly indicates that the CNT structurally is a uniform structure with ultrahigh crystallinity. The interplanar spacing values are calculated from Bragg's diffraction equation using the diffraction ring diameter and the camera length of the transmission electron microscope. The calculated results indicate the interlayer spacing in the walls, about $0.34 \mathrm{~nm}$, corresponds to the 002 distance of graphitic carbon. The EDS spectrum of the carbon nanotube shows that these are fully elemental carbon except the elements of $\mathrm{Ni}, \mathrm{P}$, and $\mathrm{Cu}$, which come from the supported grid for TEM measurement (Figure 8(c)).

The most important feature of this specific structure is related to the formation of springlike MWCNF structure. It is difficult to distinguish individual walls and graphite sheets in TEM images and even HRTEM images. XRD was performed on the annealed powder. XRD investigation (Figure 9) provided a possible model for the structure of such springlike structure. According to the XRD pattern of the sample, it is obvious that the peak of (100) is as broadening as common peak of graphite in recrystallised carbon powder, that is, (002). This indicates that the nanotubes walls are not constructed from graphite sheets. This is not the ideal hexagonal graphite as it is also oriented in c-axis parallel to the diamond anvil cell axis and suggests polytype modifications of graphite in the springlike structure. This hypothesis provides a strong reason for the formation of such outstanding structure making the springlike carbon 


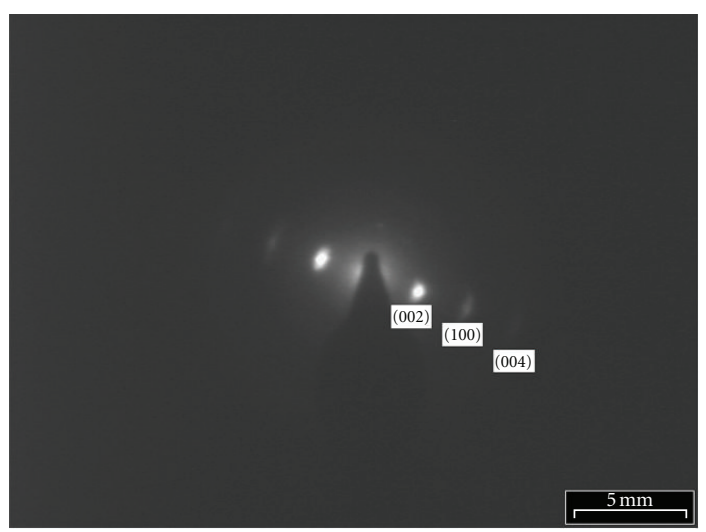

(a)

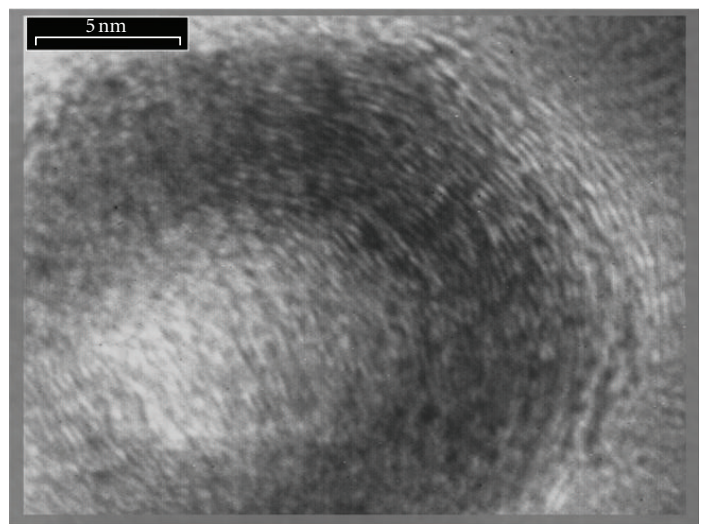

(b)

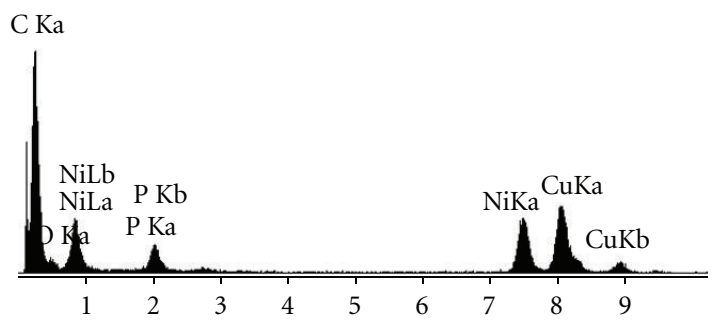

(c)

FIGURE 8: Images of MAed graphite powders for $150 \mathrm{~h}$ after annealing at $1350^{\circ} \mathrm{C}$ for $2 \mathrm{~h}$ : (a) the SAED pattern of the obtained MWCNTs, (b) HRTEM, and (c) energy dispersive spectroscopy (EDS) of the purified carbon nanotubes.

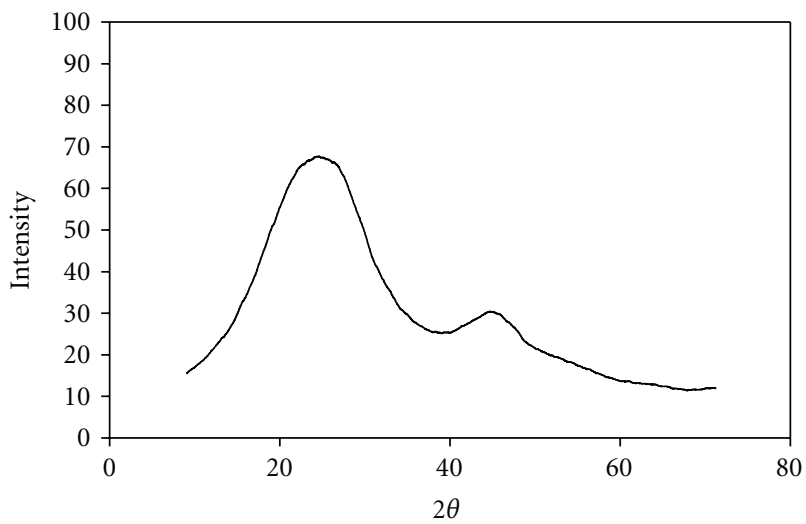

FIGURE 9: XRD Pattern of the springlike MWCNFs.

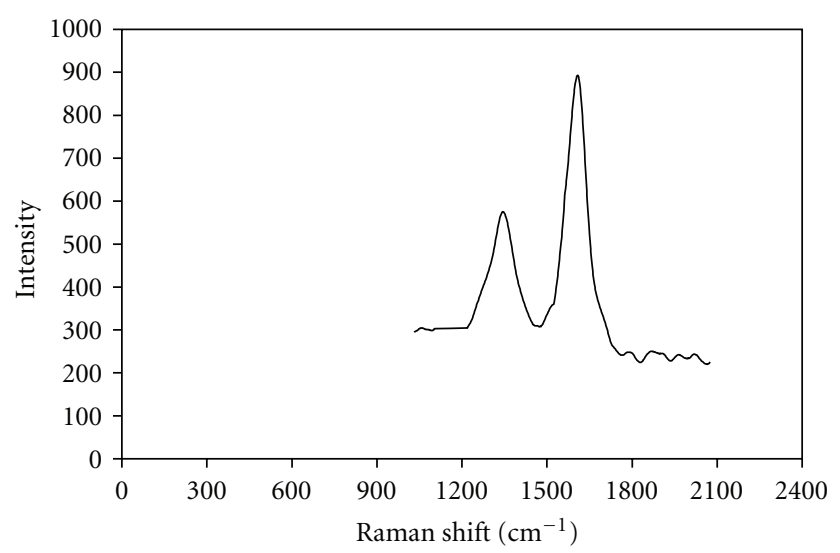

FIGURE 10: Raman spectra of the obtained MWCNTs.

nanofibers; however, the mechanism of such structure under specified mechanothermal condition is still unclear which is under investigation.

The Raman spectrum shows the D- and G-bands at 1350 and $1670 \mathrm{~cm}^{-1}$, respectively. As shown before [31], the Dband is representative for the disordered carbon structures and defects, while the G-band shows the graphitization and the crystalline properties of the nanofibers/nanotubes. The graphite-related tangential G-band [32] at $1670 \mathrm{~cm}^{-1}$ was derived from Raman-allowed optical mode, which is related to vibration in all $\mathrm{sp}^{2}$ carbon materials. The disorderinduced D-band [33] around $1350 \mathrm{~cm}^{-1}$ from the Raman spectra of $\mathrm{sp}^{2}$-bonded carbon materials is strongly dispersive as a function of laser excitation energy $\left(E_{\text {laser }}\right)$. Generally, the ratio between the intensity of the G-band and D-band $\left(I_{\mathrm{G}} / I_{\mathrm{D}}\right)$ can be used to show the structural defect and disordered carbon materials in a few micrometers scale. The $I_{\mathrm{G}} / I_{\mathrm{D}}$ ratio obtained (see Figure 10 ) was relatively high compared with that of about 2.5. The $I_{\mathrm{G}} / I_{\mathrm{D}}$ high ratio indicates the high purity of the present specimen.

\section{Conclusion}

In summary, we have successfully developed a controlled and specific method for synthesizing springlike MWCNFs and MWCNTs via a mechanothermal (MT) process. The versatility of this simple approach can be extended beyond nanotechnological purposes to many applications such as reinforcement in nanocomposite materials with desired properties and a suitable aspect ratio for improving mechanical properties. The purity and good quality of CNFs/CNTs obtained by mechanothermal method make suitable synthesis a promising method for the production of multiwall carbon nanotubes or other graphitic nanocarbons with different morphologies.

\section{Acknowledgments}

The authors would like to acknowledge Professor Anna Dash from the English Language Randwich community, Sydney, Australia, for helping in improvement of English of this paper and Mr. Jabbari for performing the experimental tests. 


\section{References}

[1] S. Iijima, "Helical microtubules of graphitic carbon," Nature, vol. 354 , no. 6348 , pp. 56-58, 1991.

[2] M. Ouyang, J. L. Huang, and C. M. Lieber, "Fundamental electronic properties and applications of single-walled carbon nanotubes," Accounts of Chemical Research, vol. 35, no. 12, pp. 1018-1025, 2002.

[3] M. M. J. Treacy, T. W. Ebbesen, and J. M. Gibson, "Exceptionally high Young's modulus observed for individual carbon nanotubes," Nature, vol. 381, no. 6584, pp. 678-680, 1996.

[4] Y. F. Yin, T. Mays, and B. McEnaney, "Adsorption of nitrogen in carbon nanotube arrays," Langmuir, vol. 15, no. 25, pp. 8714-8718, 1999.

[5] D. Li and Y. Xia, "Direct fabrication of composite and ceramic hollow nanofibers by electrospinning," Nano Letters, vol. 4, no. 5, pp. 933-938, 2004.

[6] Y. H. Li, J. Ding, Z. Luan et al., "Competitive adsorption of $\mathrm{Pb}^{2+}, \mathrm{Cu}^{2+}$ and $\mathrm{Cd}^{2+}$ ions from aqueous solutions by multiwalled carbon nanotubes," Carbon, vol. 41, no. 14, pp. 27872792, 2003.

[7] D. S. Bethune, C. H. Kiang, M. S. De Vries et al., "Cobaltcatalysed growth of carbon nanotubes with single-atomiclayer walls," Nature, vol. 363, no. 6430, pp. 605-607, 1993.

[8] T. Guo, P. Nikolaev, A. Thess, D. T. Colbert, and R. E. Smalley, "Catalytic growth of single-walled manotubes by laser vaporization," Chemical Physics Letters, vol. 243, no. 1-2, pp. 49-54, 1995.

[9] Y. M. Shyu and F. Chau-Nan Hong, "The effects of pretreatment and catalyst composition on growth of carbon nanofibers at low temperature," Diamond and Related Materials, vol. 10, no. 3-7, pp. 1241-1245, 2001.

[10] J. M. Ting and N. Z. Huang, "Thickening of chemical vapor deposited carbon fiber," Carbon, vol. 39, no. 6, pp. 835-839, 2001.

[11] M. Ritschel, M. Uhlemann, O. Gutfleisch et al., "Hydrogen storage in different carbon nanostructures," Applied Physics Letters, vol. 80, no. 16, pp. 2985-2987, 2002.

[12] V. Ivanov, J. B. Nagy, P. Lambin et al., "The study of carbon nanotubules produced by catalytic method," Chemical Physics Letters, vol. 223, no. 4, pp. 329-335, 1994.

[13] V. Vinciguerra, F. Buonocore, G. Panzera, and L. Occhipinti, "Growth mechanisms in chemical vapour deposited carbon nanotubes," Nanotechnology, vol. 14, no. 6, pp. 655-660, 2003.

[14] E. Couteau, K. Hernadi, J. W. Seo et al., "CVD synthesis of high-purity multiwalled carbon nanotubes using $\mathrm{CaCO}_{3}$ catalyst support for large-scale production," Chemical Physics Letters, vol. 378, no. 1-2, pp. 9-17, 2003.

[15] D. Lupu, A. R. Biriş, A. Jianu et al., "Carbon nanostructures produced by CCVD with induction heating," Carbon, vol. 42, no. 3, pp. 503-507, 2004.

[16] A. Okamoto and H. Shinohara, "Control of diameter distribution of single-walled carbon nanotubes using the zeoliteCCVD method at atmospheric pressure," Carbon, vol. 43, no. 2, pp. 431-436, 2005.

[17] L. Piao, Y. Li, J. Chen, L. Chang, and J. Y. S. Lin, "Methane decomposition to carbon nanotubes and hydrogen on an alumina supported nickel aerogel catalyst," Catalysis Today, vol. 2, no. 74, pp. 145-155, 2002.

[18] M. Yudasaka, R. Kikuchi, T. Matsui, Y. Ohki, S. Yoshimura, and E. Ota, "Specific conditions for Ni catalyzed carbon nanotube growth by chemical vapor deposition," Applied Physics Letters, vol. 67, pp. 2477-2479, 1995.
[19] M. M. Shaijumon and S. Ramaprabhu, "Synthesis of carbon nanotubes by pyrolysis of acetylene using alloy hydride materials as catalysts and their hydrogen adsorption studies," Chemical Physics Letters, vol. 374, no. 5-6, pp. 513-520, 2003.

[20] J. M. C. Moreno and M. Yoshimura, "Hydrothermal processing of high-quality multiwall nanotubes from amorphous carbon," Journal of the American Chemical Society, vol. 123, no. 4, pp. 741-742, 2001.

[21] Y. Chen, M. J. Conway, and J. D. Fitzgerald, "Carbon nanotubes formed in graphite after mechanical grinding and thermal annealing," Applied Physics A, vol. 76, no. 4, pp. 633636, 2003.

[22] S. Manafi, H. Nadali, and H. R. Irani, "Low temperature synthesis of multi-walled carbon nanotubes via a sonochemical/hydrothermal method," Materials Letters, vol. 62, no. 26, pp. 4175-4176, 2008.

[23] A. Eftekhari, S. Manafi, and F. Moztarzadeh, "Catalytic chemical vapor deposition preparation of multi-wall carbon nanotubes with cone-like heads," Chemistry Letters, vol. 35, no. 1, pp. 138-139, 2006.

[24] V. Bajpai, L. Dai, and T. Ohashi, "Large-scale synthesis of perpendicularly aligned helical carbon nanotubes," Journal of the American Chemical Society, vol. 126, no. 16, pp. 5070-5071, 2004.

[25] X. Chen, S. Yang, Y. Kato, and S. Motojima, "Influence of CVD conditions on the growth of carbon microcoils with circular cross-sections," Materials Letters, vol. 61, no. 14-15, pp. 29002903, 2007.

[26] S. Yang, X. Chen, S. Motojima, and M. Ichihara, "Morphology and microstructure of spring-like carbon micro-coils/nanocoils prepared by catalytic pyrolysis of acetylene using $\mathrm{Fe}-$ containing alloy catalysts," Carbon, vol. 43, no. 4, pp. 827-834, 2005.

[27] S. Yang, M. Hasegawa, X. Chen, and S. Motojima, "Synthesis and morphology of carbon microcoils produced using methane as a carbon source," Carbon, vol. 45, no. 7, pp. 15921595, 2007.

[28] X. Chen, S. Yang, S. Motojima, and M. Ichihara, "Morphology and microstructure of twisting nano-ribbons prepared using sputter-coated Fe-base alloy catalysts on glass substrates," Materials Letters, vol. 59, no. 7, pp. 854-858, 2005.

[29] G. K. Williamson and W. H. Hall, "X-ray line broadening from filed aluminium and wolfram," Acta Metallurgica, vol. 1, no. 1, pp. 22-31, 1953.

[30] Q. Jiang and Z. P. Chen, "Thermodynamic phase stabilities of nanocarbon," Carbon, vol. 44, no. 1, pp. 79-83, 2006.

[31] W. Wang, S. Kunwar, J. Y. Huang, D. Z. Wang, and Z. F. Ren, "Low temperature solvothermal synthesis of multiwall carbon nanotubes," Nanotechnology, vol. 16, no. 1, pp. 21-23, 2005.

[32] C. J. Lee, J. Park, Y. Huh, and J. Yong Lee, "Temperature effect on the growth of carbon nanotubes using thermal chemical vapor deposition," Chemical Physics Letters, vol. 343, no. 1-2, pp. 33-38, 2001.

[33] M. S. Dresselhaus, G. Dresselhaus, A. Jorio, A. G. Souza Filho, and R. Saito, "Raman spectroscopy on isolated single wall carbon nanotubes," Carbon, vol. 40, no. 12, pp. 2043-2061, 2002 . 

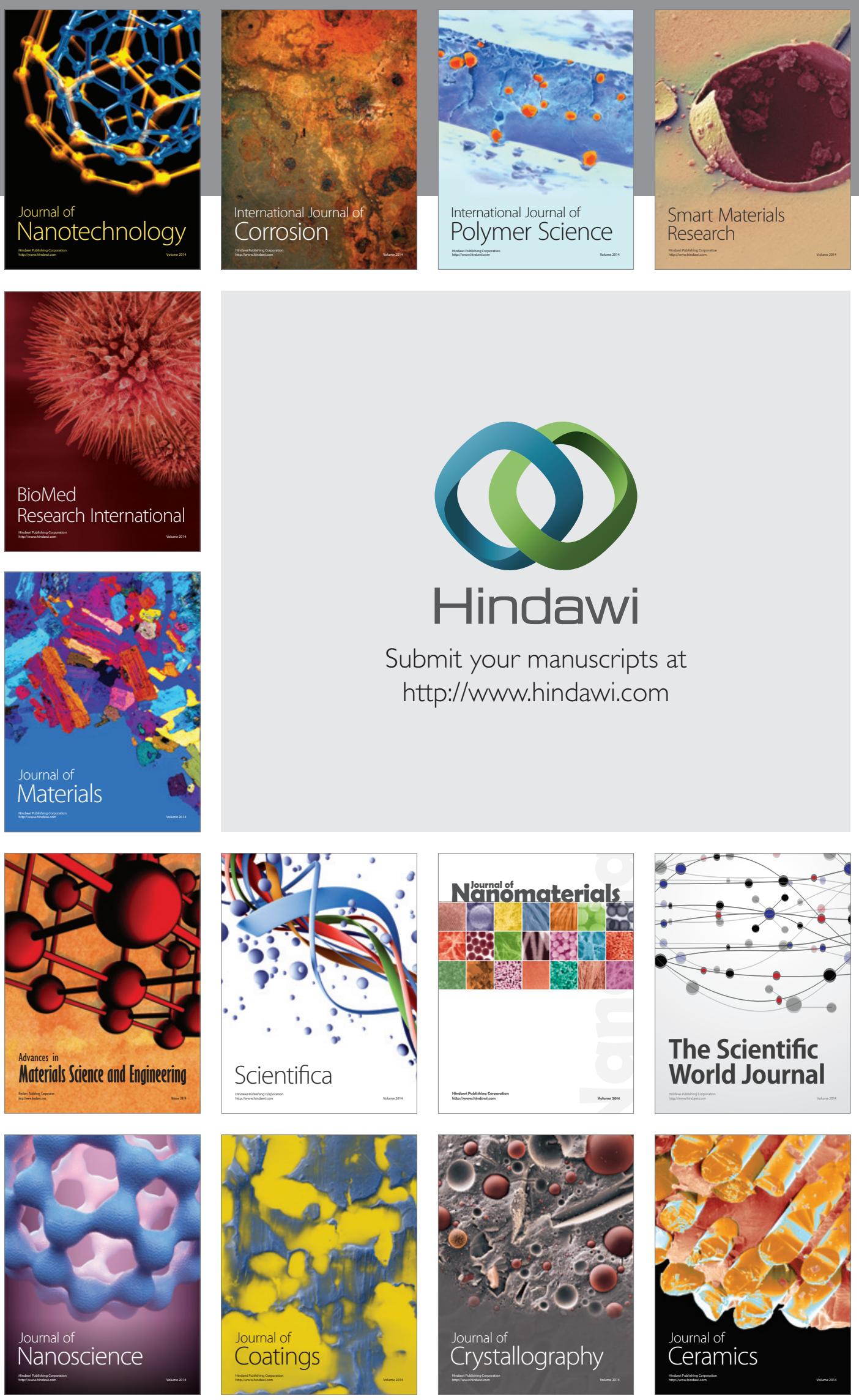

The Scientific World Journal

Submit your manuscripts at

http://www.hindawi.com

\section{World Journal}

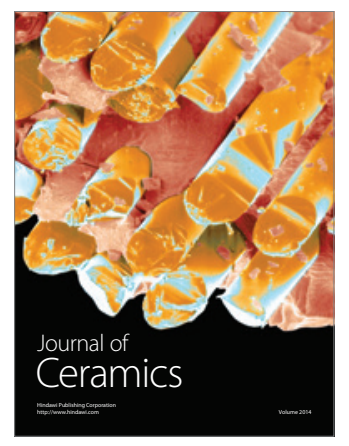

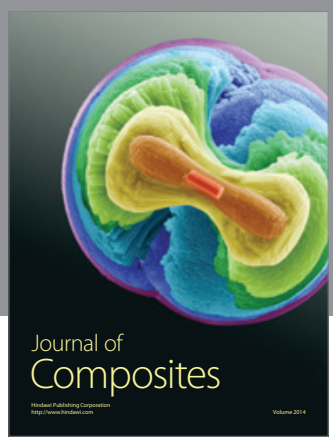
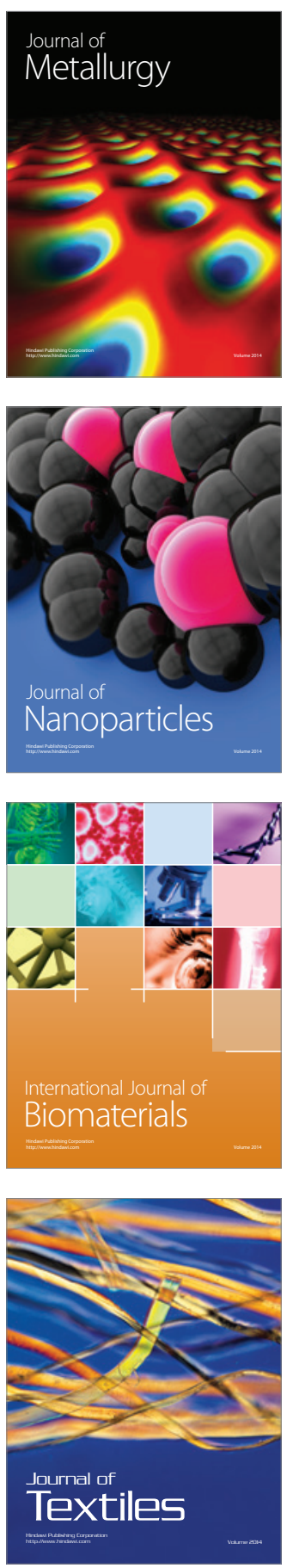